\title{
EDITORIAL
}

\author{
J. T. Katsikadelis · R. Kienzler • W. Kurnik
}

\section{Special issue on the 6th German-Greek-Polish Symposium on recent advances in mechanics}

Published online: 12 May 2009

(c) Springer-Verlag 2009

The 6th German-Greek-Polish Symposium was carried out by the Office of Theoretical and Applied Mechanics of the Academy of Athens and the Hellenic Society of Theoretical and Applied Mechanics. The Symposium was held at Hotel Thraki Palace in Alexandroupolis, Greece, from 17 September until 21 September 2007. In the series of these symposia, 15 distinguished scientists from each participating country come together and present their latest research work in the broad area of applied mechanics. The 6th German-Greek-Polish Symposium also included distinguished scientists from Italy and Serbia as "observers", who expressed interest for cooperation among their countries.

Throughout, the presentations were of the highest scientific level. This special issue of the Archive of Applied Mechanics contains most of the contributions to the symposium.

Initiated by Profs. Bogacz, Kounadis and Mahrenholtz and continued by Profs. Katsikadelis, Kienzler and Kurnik after 2000, the German-Greek-Polish Symposia are organized every 3 years by one of the organizing countries and date back from

1. September 1991 in Pultusk, Poland

2. September 1996 in Bad Honnef, Gemany

3. September 1998 in Xanthi, Greece

4. September 2001 in Pultusk, Poland

5. September 2004 in Bad Honnef, Germany

6. September 2007 in Alexandroupolis, Greece

All symposia have been successful both in terms of exchanging scientific information and extending friendship and personal interaction among the participant.

The financial support of the 6th German-Greek-Polish Symposium by the Academy of Athens, the Pericles Theocaris Foundation, the Ministry of National Education and Religious Affairs, the National Technical University of Athens, the Democritus University of Thrace and the Prefecture of Evros is gratefully acknowledged. Prof. Katsikadelis, supported by the local Organising Committee headed by Prof. Gdoutos, Democritus University of Thrace, Xanthi, enabled a smoothly running and in all aspects excellent symposium.

The 7th German-Greece-Polish symposium will be held in Poznan, Poland, in 2010.

J. T. Katsikadelis

Athens, Greece

R. Kienzler $(\bowtie)$

Bremen, Germany

E-mail: rkienzler@uni-bremen.de

W. Kurnik

Warsaw, Poland 